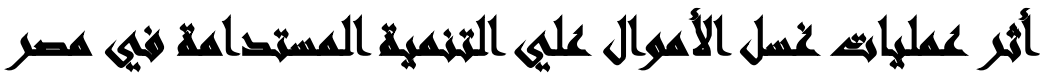

\section{[19]}

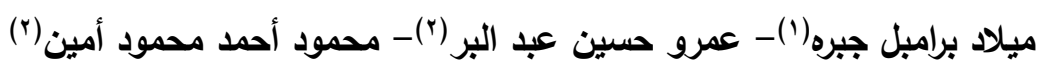

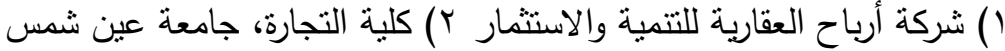

\section{المستخليه}

تهدف الدراسة إلي تسليط الضوء على الآثار السلبية لعمليات غسل الأموال على التتمية

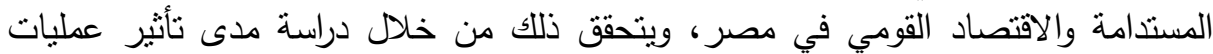

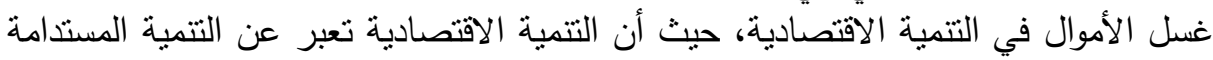

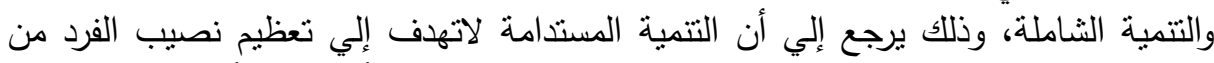

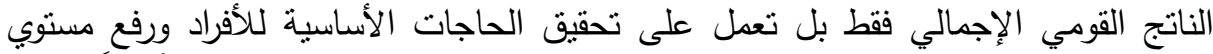

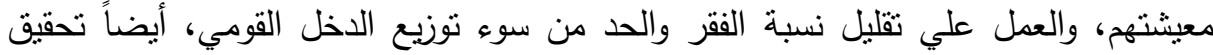

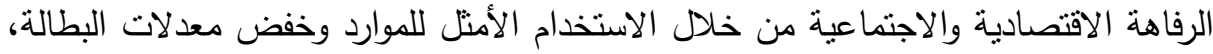

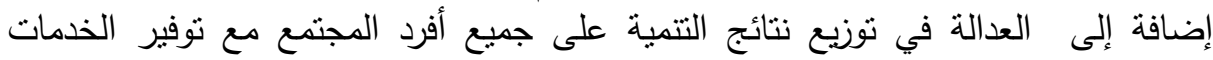

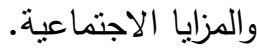
وقد اعتمد الباحثون علي التقارير والنشرات الصادرة من (صندوق النقد العبدي، نشرة

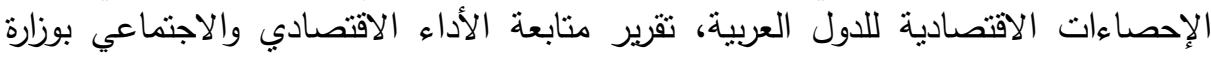

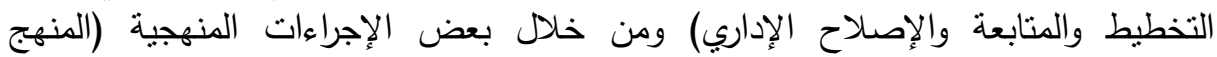

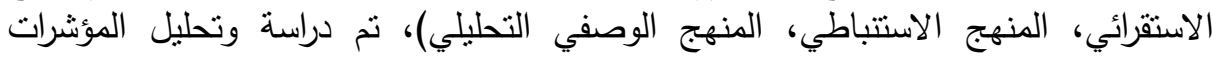

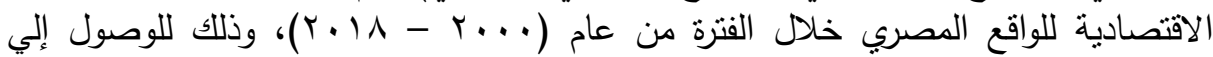

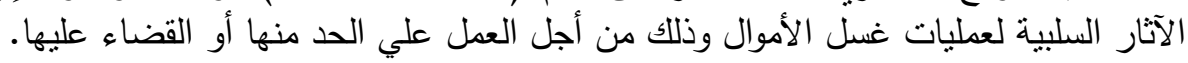
وقد توصلت الدراسة إلي النتائج الآتية :

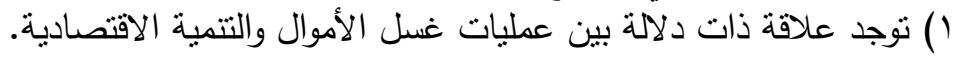

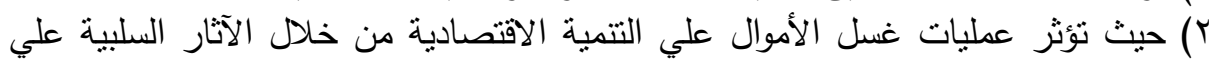
مؤشرات الاقتصاد القومي.

r) توجد علاقة ذات دلالة بين عمليات غسل الأموال والتتمية الاقتصادية.

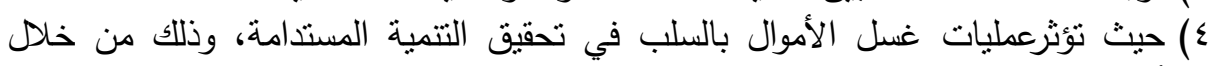
أثنرها السلبي علي التتمية الاقتصادية وتهديد الاستقرار الاقتصادي. 
ومن أهم التوصيات التي يقدمها الباحثون ما يلي :

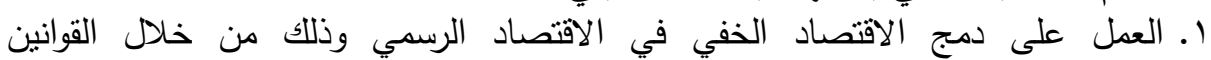

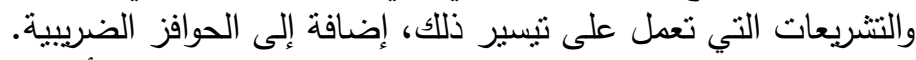

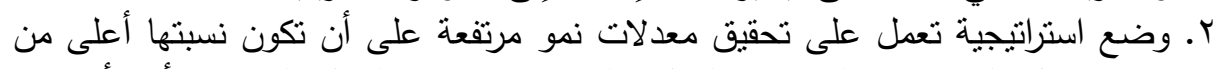

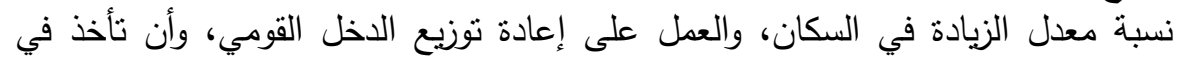

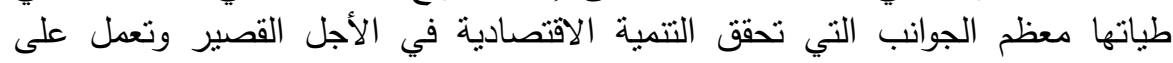
تحقيق التتمية المستدامة في الأجل الطويل.

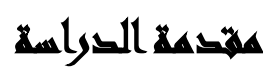

تُعدّ عمليات غسل الأموال أحد أكبر العقبات التي تحول دون تحقيق التتمية الاقتصادية الفعًالة التي تؤدي إلى تحقيق التتمية المستدامة، ولعمليات غسل الأموال مشاكل اقتصادية واجتماعية، لأنها عبارة عن مجموعة من الأنشطة التي تتم بعيداً عن خطة التنمية

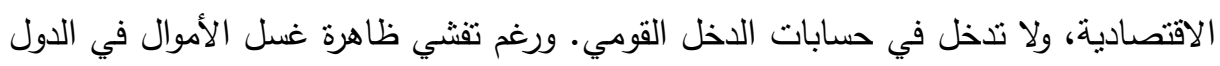
الغربية، إلا أن المسئولين عنها غالباً ما يتربصون بالأسواق الناشئة والدول النامية التي تسعي التهي لفتح أسواقها للاستتمارات الأجنبية المباشرة.

تؤدي عمليات غسل الأموال إلى إعاقة قدرة الحكومات للسيطرة على سير الخطط

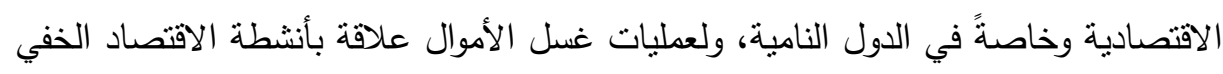

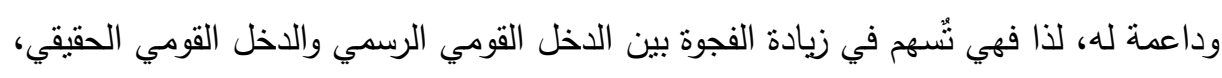

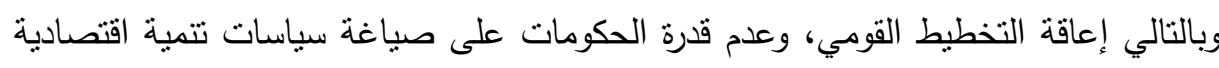

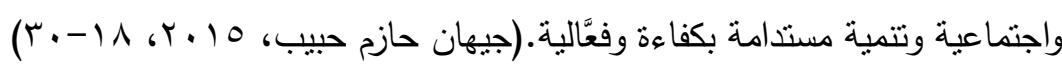

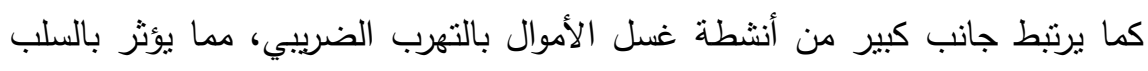

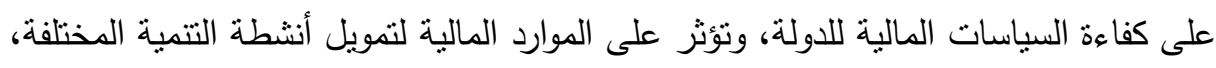

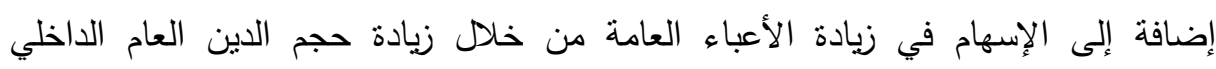
والخارجي مما يؤدي إلى فرض المزيد من الضرائب لدعم السياسات المالية للدولة، وهذا يؤثن

$$
\text { بالسلب على الاقتصاديات الوطنية. }
$$

تؤثر عمليات غسل الأموال بالسلب على التتمية الاقتصادية التي تعد الأساس لتحقيق

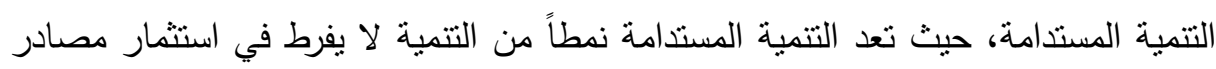
492

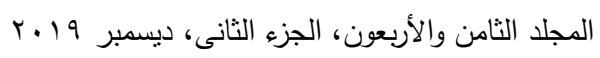


الثروات الطبيعية التي ترتكز عليها التتمية، أي أن التتمية المستدامة تعمل على تجديد الموارد والثروات بشكل يضمن بيئة صالحة للأجيال الحاضرة والقادمة.

أيضاً تعد التتمية المستدامة الضابط الرئيسي للسياسات الاقتصادية في تعاملها مع البيئة والثروات الطبيعية التي تؤدي إلى شعور الإنسان بالأمان والاستقرار ، بعد أن كان الأعتقاد بأن

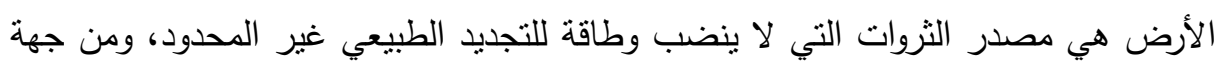
أخرى، تمثل التتمية المستدامة الفرصة الجديدة لنوعية النمو الاقتصادي وكيفية نوزيع منافعه

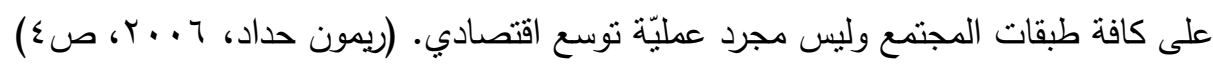

\section{هم:حلالة التراسمة}

تؤدي عمليات غسل الأموال الناتجة من مجالات اقتصادية سيئة إلى أثار سلبية، لأنها تتم عن طريق نقل أموال ناتجة من معاملات مشبوهه (مثل تجارة المخدرات والأسلحة) في

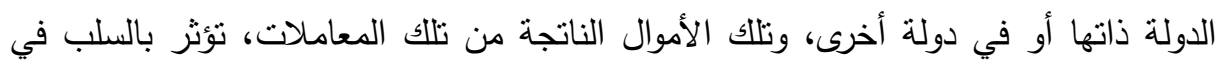

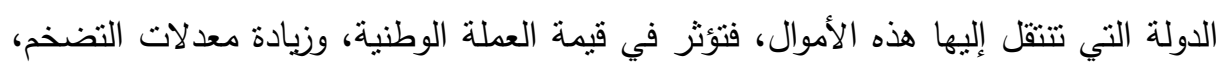

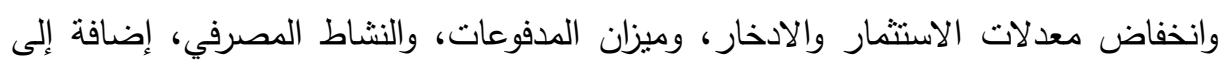

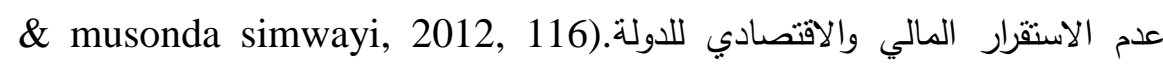
(muhammed haseed

فالأموال الناتجة عن عمليات غسل الأموال هي أموال غير مشروعة ومتحصلة من

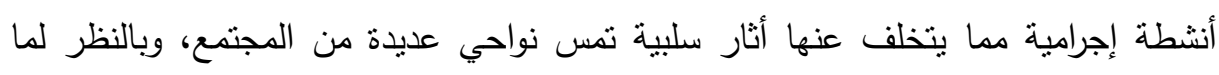

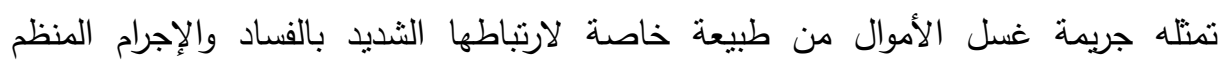

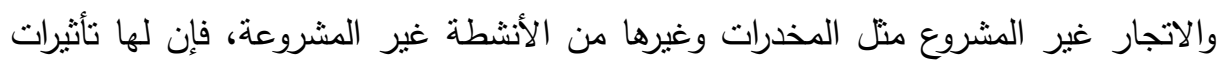

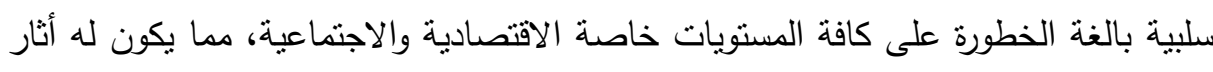

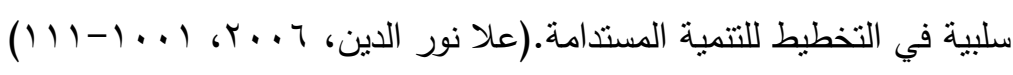

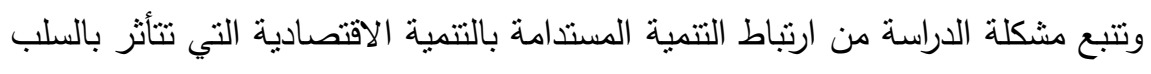
من عمليات غسل الأموال، كما أنها تؤثر على تحقيق التوازن بين النظام البيئي والاقتصادي لئي

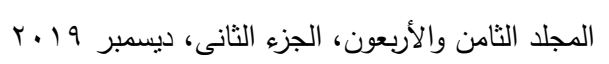


والاجتماعي مما يؤثر على الاقتصاد القومي وقد أعتمدت الدراسة على كل من المنهج

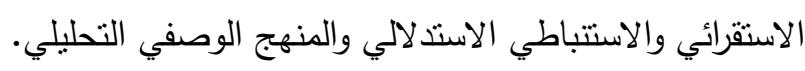

\section{أسهئل التصواسمة}

( ) إلي أي مدي يؤثر غسل الأموال على الاقتصاد القومي؟

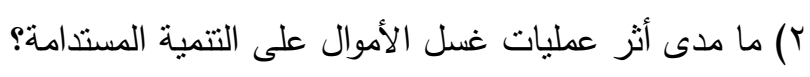

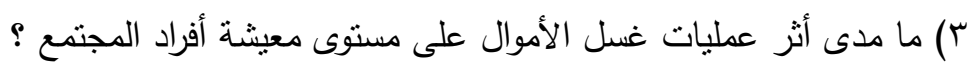

\section{أهمية الصواسمة}

\section{يمكن تحديد الأهمية العلمية والتطبيقية على النحو التالي:}

- من الناحية العلمية: تتمثل الأهمية العلمية للدراسة في معرفة أثر عمليات غسل

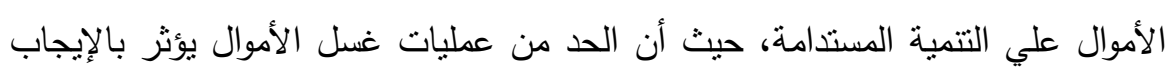

في معدلات النمو الاقتصادي، ويساهم في تحقيق أهداف التتمية المستدامة.

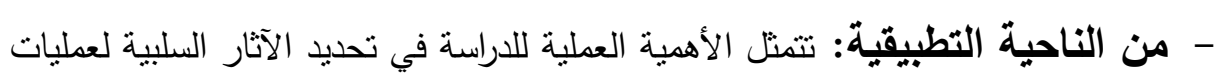
غسل الأموال علي الاقتصاد القومي والتي بدورها تؤثر علي تحقيق التتمية المستدامة.

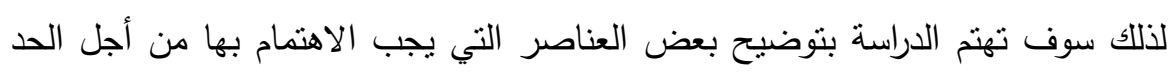

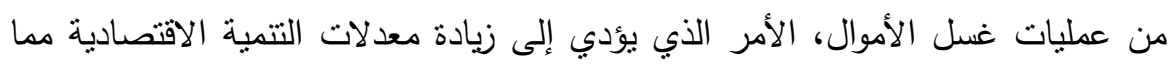
يؤثز بالإيجاب على الصعيدين المحلي والدولى على النتمية المستدامة.

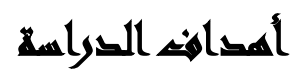

الهدف الأساسي للاراسة: هو تسليط الضوء على الأثار السلبية لعمليات غسل الأموال

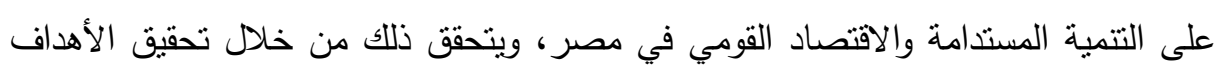
الفرعية التالية: - التئ

- - دراسة مفهوم عمليات غسل الأموال.

- دراسة مدي ارتباط عمليات غسل الأموال بالتتمية المستدامة.

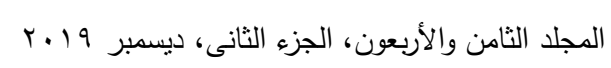


- بيان أثز عمليات غسل الأموال على التتمية المستدامة والاقتصاد القومي.

\section{هزوض الصراسلة}

تم صياغة الفروض التالية كأسباب محتملة للمشكلة محل الاراسة كالتالي: الفرض الأول: لا توجد علاقة ذات دلالة معنوية بين عمليات غسل الأموال والتتمية الاقتصادية. الفرض الثاني: لا نوجد علاقة ذات دلالة معنوية بين عمليات غسل الأموال والتتمية

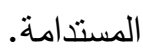

\section{السراسايس السابرية}

أولاً: الدراسات السابقة المتعلقة بغسل الأموال: - دراسة (Jeffrey Simser, 2017): وقد هدفت الداسة إلى فهم أنماط وتقنيات لمواجهة تحديات غسل الأموال، ومعرفة التحديات والمخاطر التي يشكلها غسل الأموال على النظم المالية حتي في ظل وجود سيادة القانون. أيضاً تحديد الآثار السلبية لعمليات غسل الأموال، وكيفية تطبيق الجهات التنظيمية لنظم مكافحة غسل الأموال، وتوفير التدابير لفحص مدي فعالية نظم مكافحه غسل الأموال، وتوفير التدابير لفحص مدي فعالية نظم

$$
\text { مكافحه غسل الأموال. }
$$

- دراسة (Norman Mugarura, 2016) وق هدفت الدراسة إلى نوضيح أن أنظمة الحظر العالمية غير المحدة مثل أنظمة مكافحة غسل الأموال، وتوضيح النطاق الواسع الذي يتم فيه وضع مفاهيم جرائم غسل الأموال وتطبيقها من قبل جهات قضائية مختلفة وتحدياتها المتأصلة، أيضاً تحديد نطاق القضايا التي غالباً ما نوضح الخلافات المنأصلة في بعض المجالات عن طريق قانون ( PATRIOT 2001 ونموذج "اعرف عميلك". 
حيث أن عدم وضوح الإطار التنظيمي للمؤسسات المصرفية وخاصةً على نطاق واسع من شأنه أن يسبب الارتباك والخلافات في العمل المصرفي. - دراسة (Michel Dion, 2015): وقد هدفت الدراسة إلى وصف المواقف الفلسفية المختلفة حول أنشطة غسل الأموال، اعتمادًا على الطريقة التي ننظر بها إلى الأخلاق

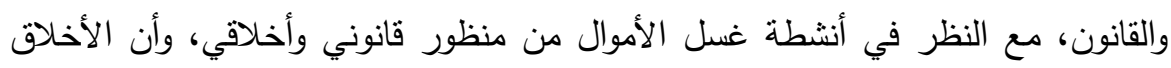

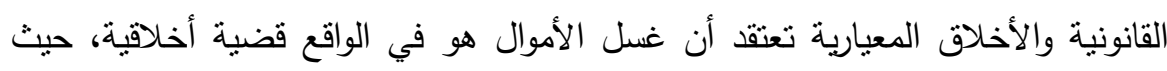

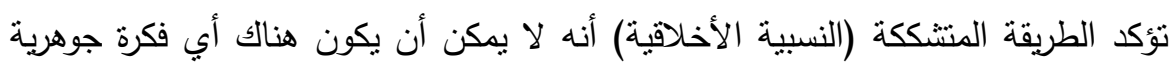

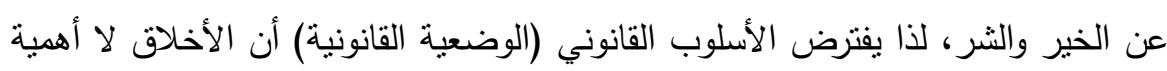

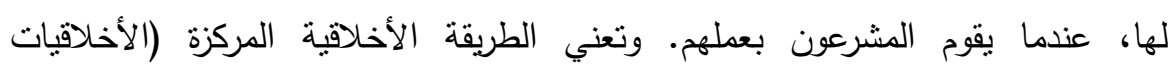

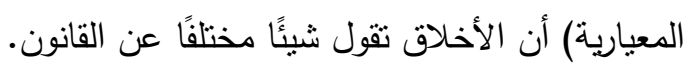
- دراسة (M.Michelle Gallant, 2014) وقت هدفت الدراسة إلى أخذ منظور تحليلي شامل على مدى أربعة عقود من تتظيم برنامج مكافحة غسل الأموال، واستخراج التأثثرات

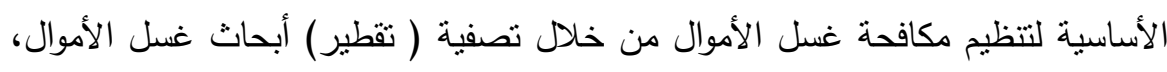

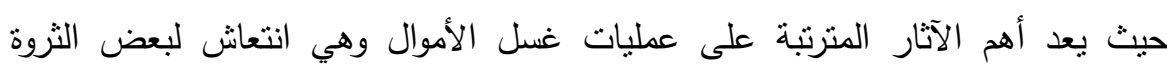
الملوثة. ويرجع ذلك إلي وجود بعض التشوهات في القانون الدولي.

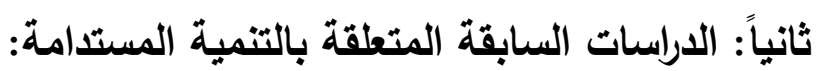
- دراسة (Joyeeta Gupta, 2017) وقد هدفت الاراسة إلى تحليل التتمية الثاملة لأهداف التتمية المستدامة، والعمل علي تتفيذ أهداف التتمية المستدامة من خلال تحدي

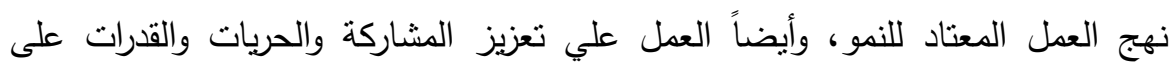
جميع المستويات التي تهدف الي تحقيق أهداف التتمية المستدامة. حيث أن تحليل التنمية

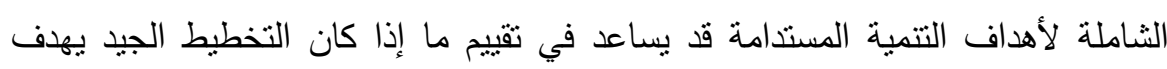

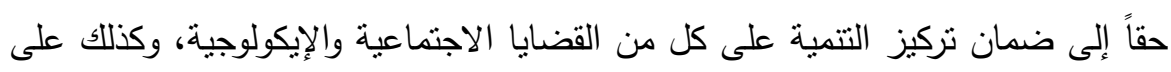
الأدوات السياسية لتحقيق التحول الذي تهدف إلى إليه. - دراسة (Elisabeta-Emilia, 2016) وقد هدفت الدراسة إلى الحفاظ على الموارد

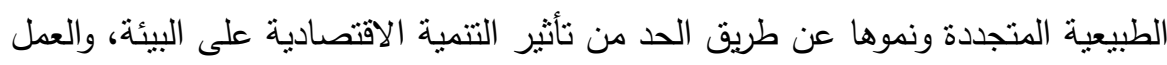


من أجل (تقليل / القضاء) على الفقر وخلق ظروف مواتية لتلبية احتياجات الحياة من(الغذاء، الماء، العمل، مكان المعيشة، الطاقة، الصحة) واتخاذ القرارات المتكاملة بشأن النمو الاقتصادي والبيئة وموارد الطاقة. ومن أجل تحقيق ذلك، تتطلب التتمية المستدامة

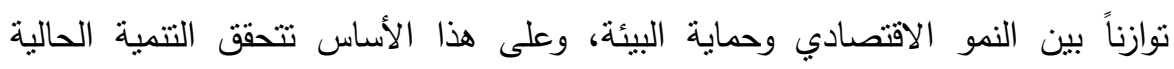
والمستقبلية. - دراسة (Vera Mignaqui, 2014) وقد هدفت الدراسة إلى اقتراح أداة تقييم متعددة المعايير تساعد في ثقيم أداء البلدان نحو التتمية المستدامة، من خلال تحديد أبعاد التتمية

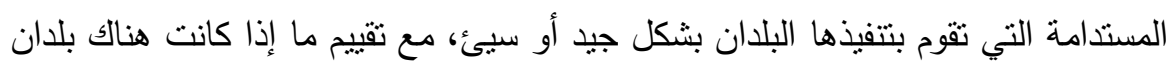

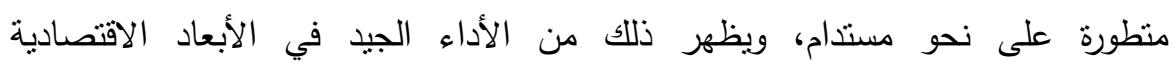
والاجتماعية والبيئية في آن واحد، وفهم العلاقات بين الأبعاد، والعمل علي تحسين أداء

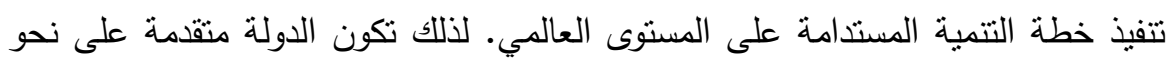

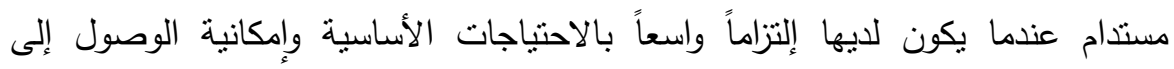
الوسائل الاقتصادية مع الحفاظ على الحدود الإيكولوجية.

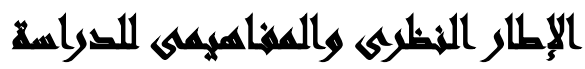

تتاولت الدراسة مجموعة من المفاهيم للتوضيح (الاقتصاد الخفي، غسل الأموال، التتمية المستدامة، البعد الاقتصادي، البعد البيئي، البعد الاجتماعي، التتمية، النمو ).

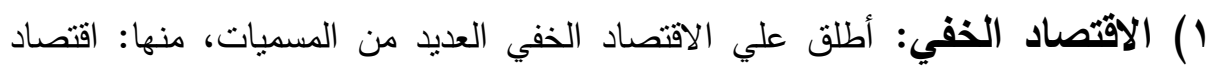
الظل أو الاقتصاد غير الرسمي أو الاقتصاد الموازي أو الاقتصاد السري، كما يمكن أن الن النادئ

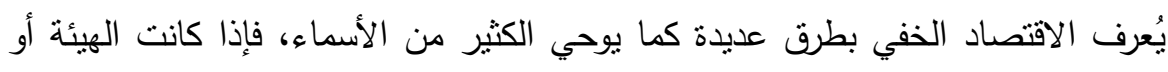

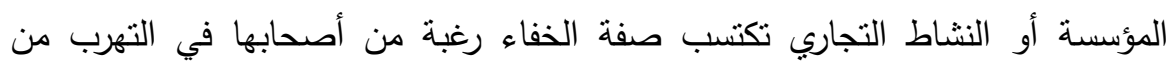

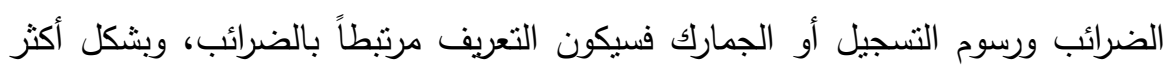

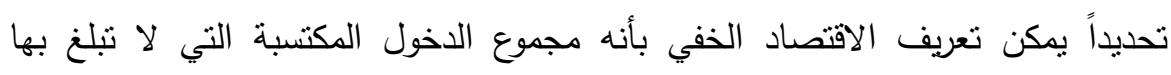

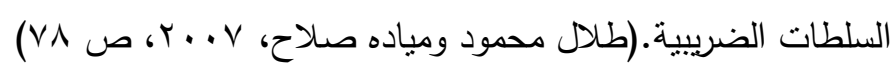


r غسل الأموال: غسل الأموال عبارة عن جريمة بيضاء عابرة للحدود الدولية وبشكل منظم، يقوم بمقتضاها احد الأشخاص بسلسلة من العمليات المالية المتلاحقة على هذه

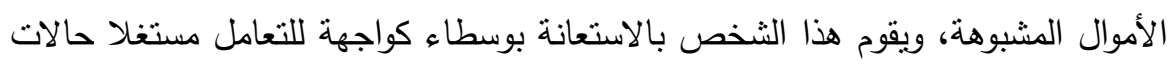
التسيب والفساد الإداري، وذلك من خلال الحسابات المصرفية وينم تأمين هذه الأموال من المتابعة القانونية والأمنية، وهذه العملية تتم من أجل تصريف ونائ عائدات الجريمة، من خلاد

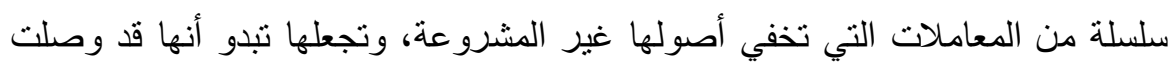
من مصدر شرعي. Kim-Kwang Raymond, 2012, \& (Angela Samantha

الفرق بين غسل الأموال والاقتصاد الخفي: إن كان كلاً من الاقتصاد الخفي وعمليات غسل

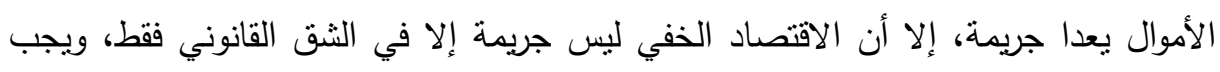

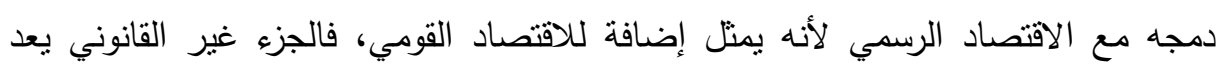

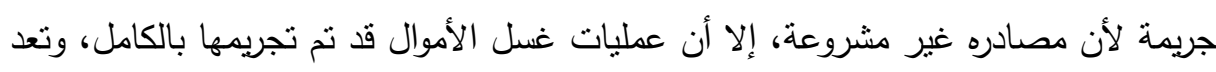

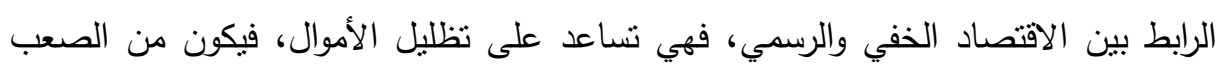

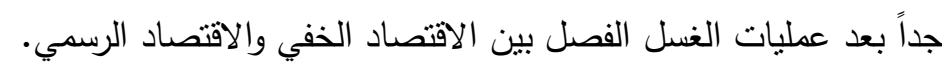
r) التنمية المستدامة: هي تطور فيزيائي للنظام الاجتماعي - الاقتصادي، مما يضمن أن الثأثير على البيئة الطبيعية لن يكون ذات أهمية في المدى الطويل، ويجب أن يكون

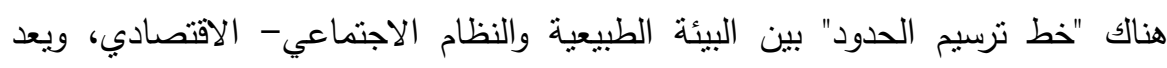
التفاعل بين البيئة الطبيعية والنظام الاجتماعي الاقتصادي تفاعلاً أساسياً في التتمية

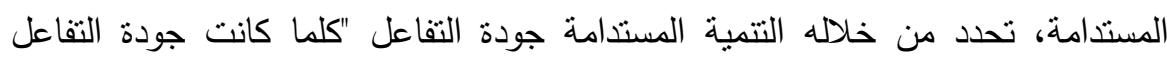

أفضل كلما كانت التنمية المستدامة أفضل". ( Darius Jazepčikas, 2013, 28 ( ع) البعد الاقتصادي: هو الذي يستهدف الخطط الاقتصادية للتتمية المستدامة عدة

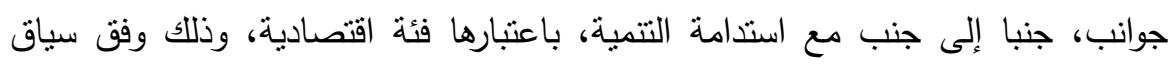

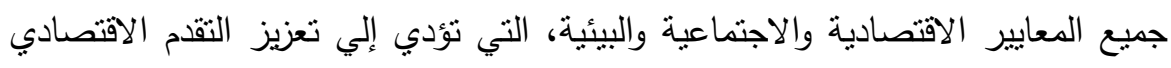

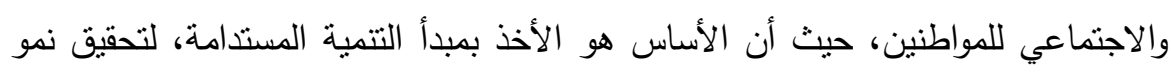
اقتصادي مستقر ، للتتمية الاجتماعية وحماية البيئة 
.( Aleksandar Nikolovski, 2013, 6-17)

•) البعد البيئي: هو الذي بركز على حماية وسلامة النظم الايكولوجية وحسن التعامل مع

الموارد الطبيعية وتوظيفها لصالح الإنسان من دون إحداث خلل في مكونات البيئة المتضمنة للأرض والماء والهواء، وما يكمن فيها من مصادر طبيعية تسهم في بقاء الحياة

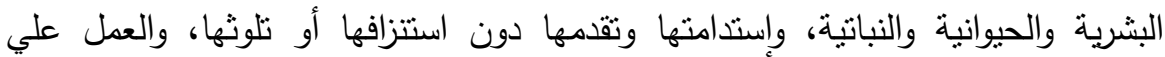

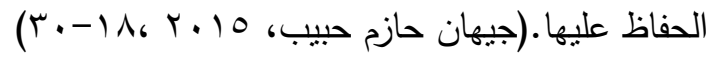

7) البعد الاجتماعي: هو الحفاظ على استقرار النظم الاجتماعية والتربوية والثقافية، من أجل تحديد الإنصاف بين الأجيال والثقافات، من خلال الحفاظ على التتوع الثقافي وتتجيع التهائ

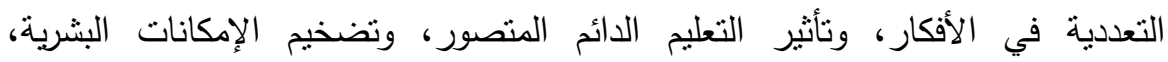
وتحسينها والعمل علي التحسين والكفاءة، وزيادة العمالة، وتوفير الغذاء، والمسكن، والتعليم والصحة في أي وقت، ورفع مستوى الدخل عن طريق تعزيز جميع الأنشطة البيئية والثقافية.

(Navabakhsh \& Tamiz, 2013, 193-194)

V التنمية: هي إجراءات وسياسات وتدابير متعددة تتمنل فى تغير بنيان وهيكل الإقتصاد القومى وتهدف إلى تحقيق زيادة سريعة ودائمة فى متوسط الدخل الحقيقى للفرد، عبر فترة ممتدة من الزمن، وبحيث يستقيد منها جميع أفراد المجتمع. ^) النمو: هو الزيادة الكمية فى متوسط الدخل الفردى الحقيقى الذى برتبط بحدوث تغيرات

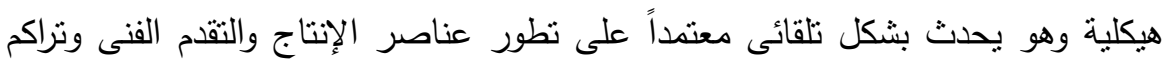
رأس المال، هو يشير إلي التغير في حجم الاقتصاد، بينما التتمية تعني التركيز ليس فقط لطي علي حجمه، بل أيضاً علي التغيرات في هيكله القطاعي لصالح القطاعات الأكثر تأميناً لنطوره، وهي القطاعات الأكثر حركية (ديناميكية) علي امتداد أجل طويل، والقطاعات

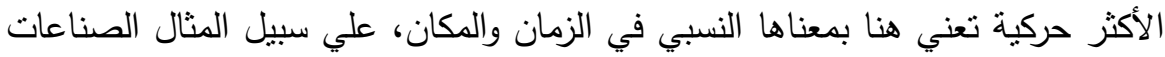

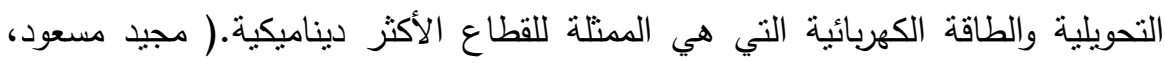




\section{اجبراعاهت القراسمة}

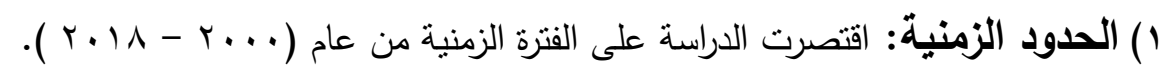
r) الحدود المكانية: جمهورية مصر العربية.

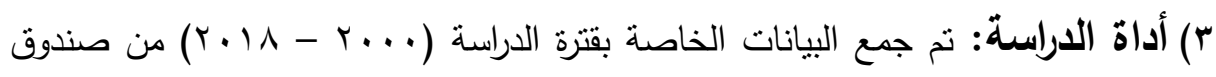
النقد العربي ونشرة الإحصاءات الاقتصادية للدول العربية، وتقرير متابعة الأداء الاقتصادي والاجتماعي وزارة التخطيط والمتابعة والإصلاح الإداري.

\section{منهبيه الصراسهة}

أولاً: أسلوب الدراسة: تعتمد منهجية الدراسة على: 1-المنهج الاستقرائي: حيث يعتمد هذا المنهج على الدراسات المكتبية والكتب والدوريات العربية والأجنبية والأبحاث والمقالات الموثقة والمنشورة. وكذلك البيانات والإحصائيات المتعددة من المصادر المختلفة. علماً بأن هذا المنهج يقوم بتعقب الظاهرة تاريخياً

$$
\text { وتفسيرها. }
$$

ب-المنهج الاستتباطي والاستدلالي: حيث يعتمد المنهج الاستتباطي الاستـلالي على تحليل

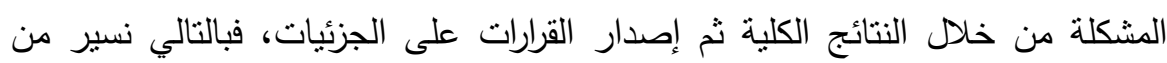

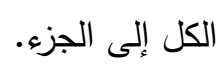

r-المنهج الوصفي التحليلي: وذلك من أجل التعرف على أبعاد مشكلة الدراسة ورصد

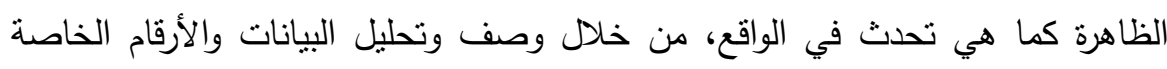
بمؤشرات الاقتصاد القومي، ووضعها في إطارها الصحيح، وذللك للوصول إلى النتائج، وبلورة الحلول الني تتمنل في النوصيات والمقترحات التي يسوقها الباحث لإنهاء الجدل الذي يتضمنه منن الدراسة. • الاراسة النظرية: حيث اعتمد الباحث على مجموعة من التقارير والنشرات والأدلة الاقتصادية والمالية عند جمع البيانات الثانوية اللازمة للاراسة، وقد نم تجميع البيانات ذات اعلى

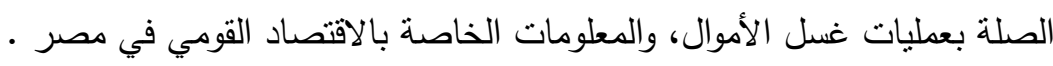


Analytical الدراسة التطبيقية: تعتمد الدراسة علي المنهج الوصفي التحليلي Descriptive Approach البحوث والدراسات الخاصة تلك التي تتتاول ظواهر اجتماعية تتعلق بالممارسات اليومية

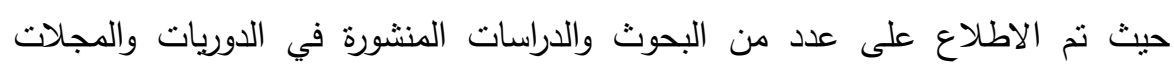
العلمية المتخصصة. بالإضافة إلى الاطلاع على الدراسات الخاصة بعمليات غسل الاطل الأموال والتتمية المستدامة وأيضاً الإحصائيات المتعلقة بالاقتصاد القومي. الإطي.

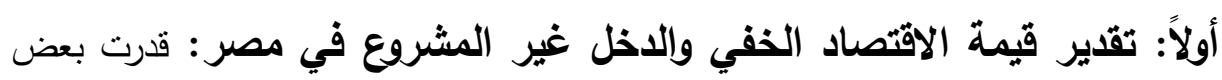

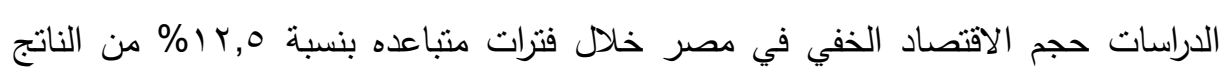

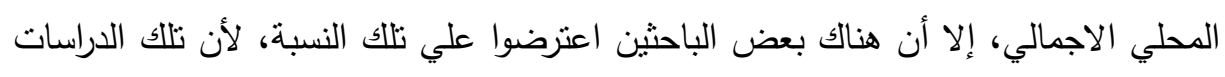

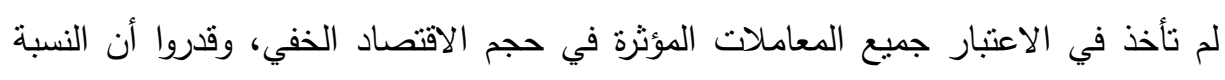

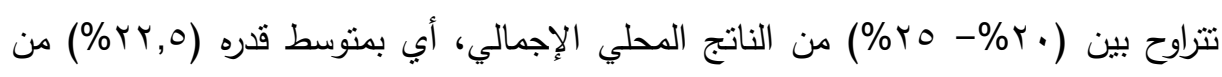

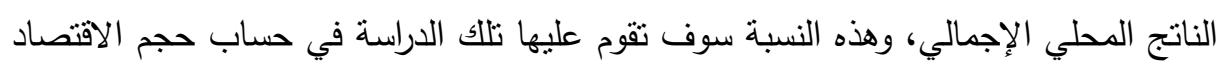

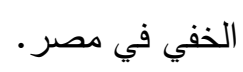
علماً بأن نسبة حجم الدخل غبر المشروع تقدر بنسبة (•0\%) من حجم الاقتصاد

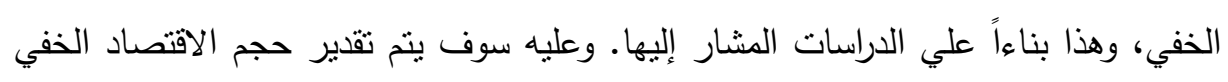

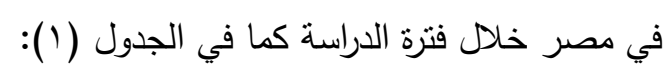




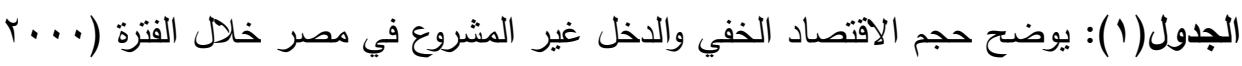

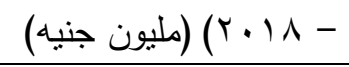

\begin{tabular}{|c|c|c|c|c|}
\hline 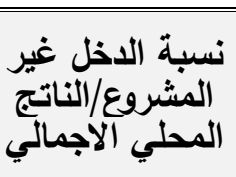 & حجم الاخل غير & حجم الاقتصاد & الألمح الناتجى & السنة \\
\hline $11, r$ & rАYTI,r & VTOYY,O & $r \varepsilon, 1 \ldots$ & Y... \\
\hline $11, r$ & $\varepsilon \cdot r \circ \mu, \Lambda$ & $\Lambda \cdot V \cdot V, 0$ & rosv.. & $r \ldots 1$ \\
\hline $11, r$ & $\varepsilon r \neg \cdot r, \Lambda$ & AOY.V,O & rVAV.. & $r \ldots r$ \\
\hline $11, r$ & $\sum 797 \wedge, \wedge$ & $9 \mu q \mu V, 0$ & $\varepsilon 1 \vee 0 \ldots$ & $r \ldots r$ \\
\hline $11, r$ & $0 \leqslant 097, r$ & $1.9194,0$ & $\varepsilon \wedge O \mu .$. & $r \ldots \varepsilon$ \\
\hline$\pi, r$ & $7.011, r$ & IYוTY,O & OrAO.. & Y..o \\
\hline $11, r$ & $79 \leq 91, r$ & 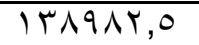 & TIVV.. & $Y \ldots T$ \\
\hline$\pi, r$ & ArVq.,. & $17 \vee 0 \wedge \cdot, \cdot$ & $V \leqslant \leqslant \wedge \ldots$ & $\overline{Y . . P V}$ \\
\hline $11, r$ & $\ldots V \varepsilon r, \Lambda$ & $r \cdot I \leqslant \wedge V, 0$ & $1900 \ldots$ & $\overline{r \cdots A}$ \\
\hline $11, r$ & $\Pi V Y \leqslant V, 0$ & $T r \leqslant \leqslant 90, \cdot$ & $1 . \Sigma Y Y \ldots$ & r..9 \\
\hline $11, r$ & IrOV $\{Y, 0$ & $r V \backslash \leqslant \wedge 0, \cdot$ & $1 Y .77 \ldots$ & Y.1. \\
\hline $11, r$ & $10 \leqslant Y \leqslant \Lambda, \Lambda$ & $r \cdot \wedge \leqslant q \vee, 0$ & $|r V| 1 \ldots$ & $r .11$ \\
\hline $11, r$ & $I V V Y \leq r, \Lambda$ & $r 0 \leq \varepsilon \lambda V, 0$ & $10 \vee 00 \ldots$ & $Y . I Y$ \\
\hline $11, r$ & $19 V Y \leq 7, r$ & $r q \leq \leqslant q r, 0$ & IVOKT.. & $r .1 T$ \\
\hline $11, r$ & TMqтYO,. & $\Sigma \vee 9 Y 0 \cdot, \cdot$ & YIr... & Y. I \\
\hline $11, r$ & $Y \vee \leqslant 94 \wedge, \Lambda$ & $0 \leqslant 9 \wedge \vee \vee, 0$ & $r \leqslant \leqslant r q \ldots$ & $r .10$ \\
\hline $11, r$ & $r \cdot \Sigma \Lambda \cdot V, 0$ & $7.9710,$. & TV.9ะ.. & T.17 \\
\hline $11, r$ & $r q . r \vee \sigma^{\prime}$. & $\vee \wedge \cdot \vee O_{,}, \cdot$ & $r \leqslant v \ldots$ & T.IV \\
\hline $11, r$ & $\sum q 9 r \cdot V, 0$ & $99 \wedge \leqslant 10, \cdot$ & $\varepsilon \leqslant \mu V \varepsilon \ldots$ & $Y .11$ \\
\hline
\end{tabular}

المصدر: بيانات الناتج المحلي الإجمالي مصدرها صندوق النقد العربي، نشرة الإحصاءات الإقتصادية للاول العربية، أعداد مختلفة. اما باقي بيانات الجدول تمت بمعرفة الباحثون. حجم الاقتصاد الخفي

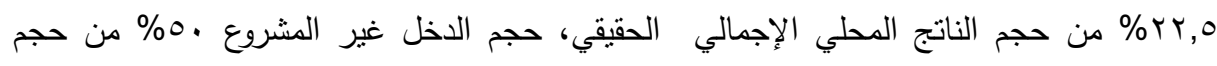

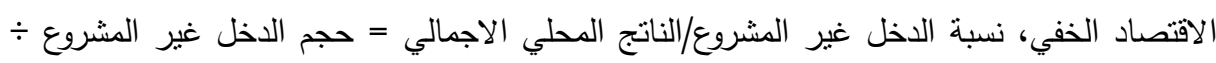

$$
\text { من الجدول الناتج المحلي الإجمالي الحقبقي. }
$$

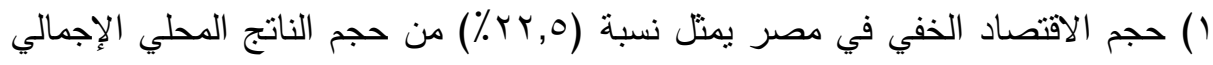

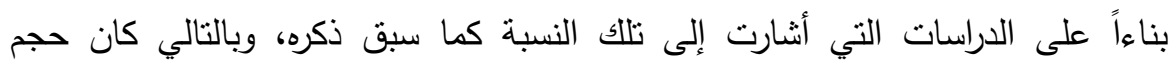

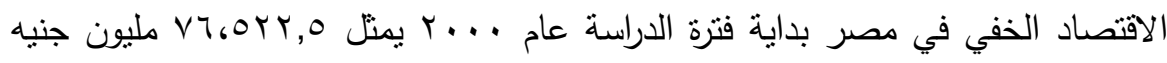




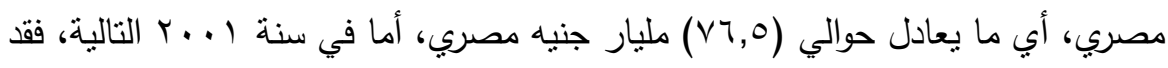

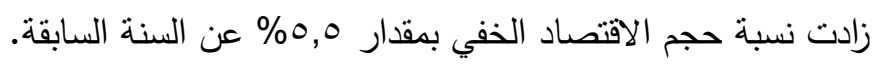

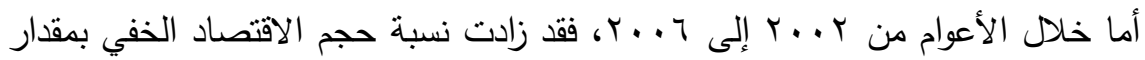

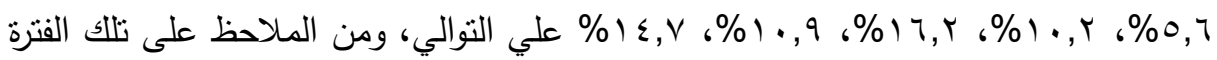

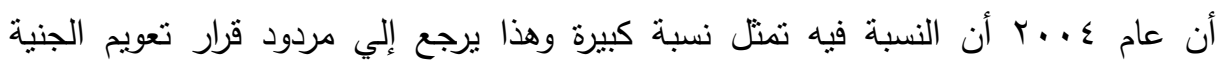

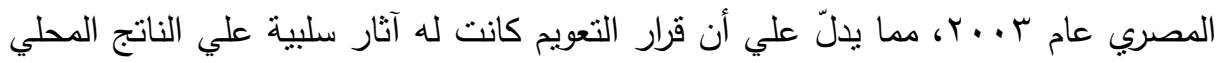
الإجمالي وزاد من نسبة الاقتصاد الخفي.

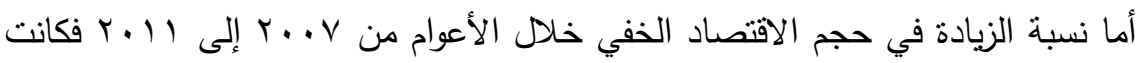

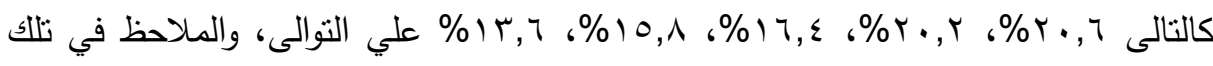

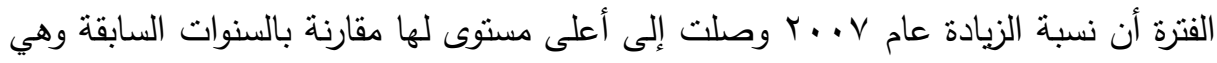

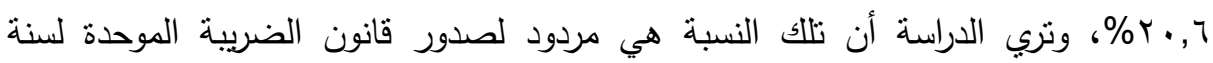

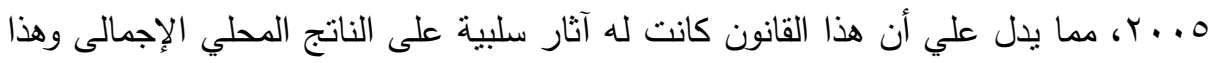
عكس ما أراده القانون، بل إن هذا القانون أدى إلى زيادة حجم الاقتصاد الخفي.

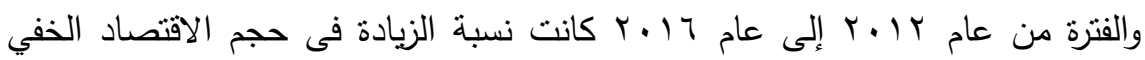

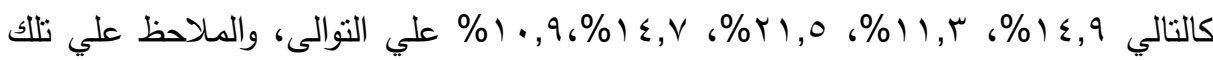

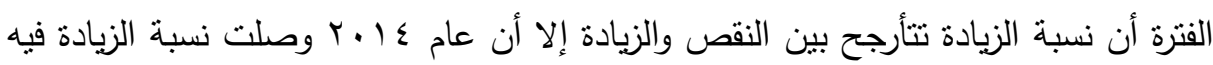

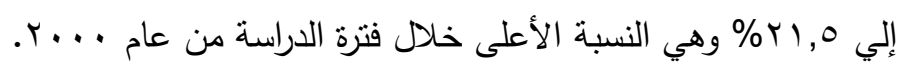

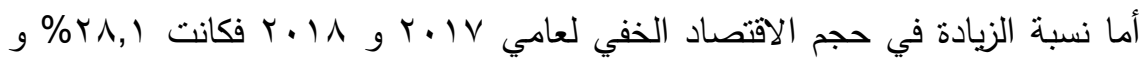

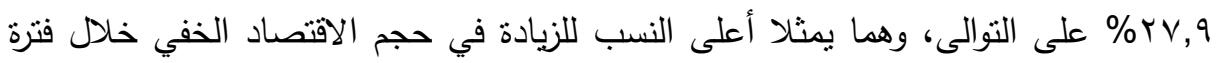
الدراسة كلها، وهذا يدل علي أن نسبة الزيادة في حجم الاقتصاد الخفي في مصر في في زيادة

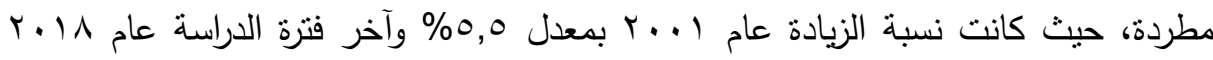
بمعدل 9rV,9\% و وهذا يدل على أن حجم الاقتصاد الخفي في زيادة، لذا ترى الدراسة أنه يمكن

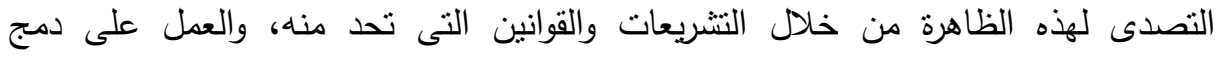
الاقتصاد الخفي في الاقتصاد الرسمي. 


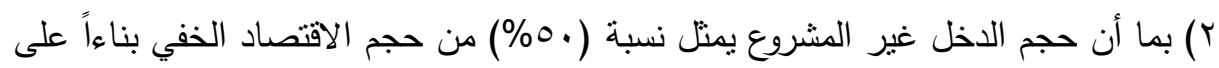

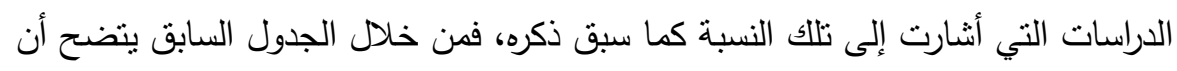

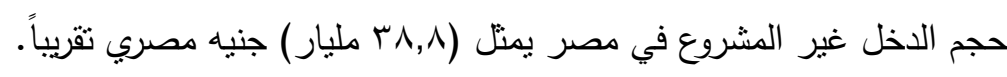

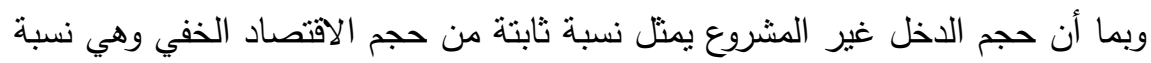

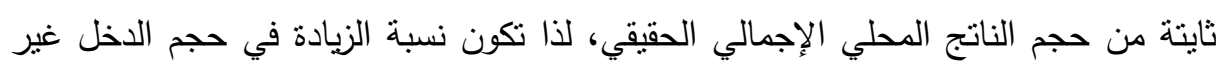

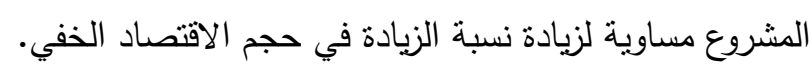

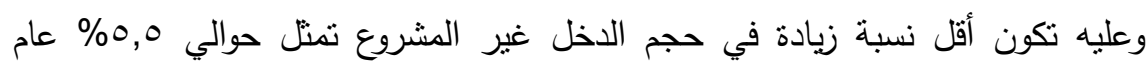

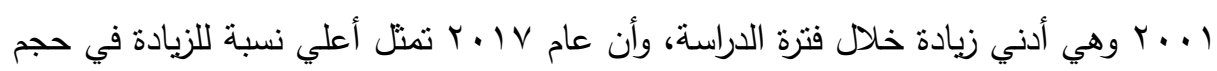

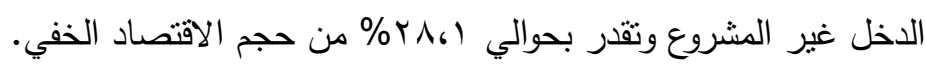

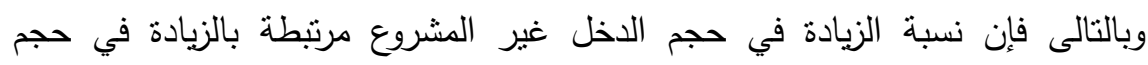

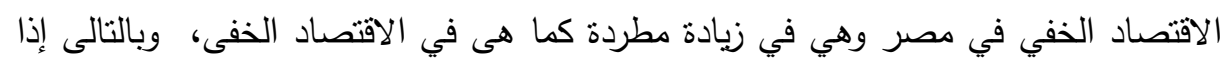

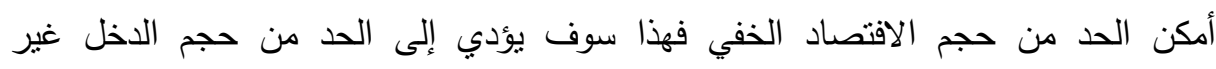

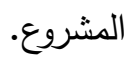
r) ومن الجدول يتضح أن نسبة الذخل غير المشروع نقدر بحوالي (r,1) (1\%) من الناتج

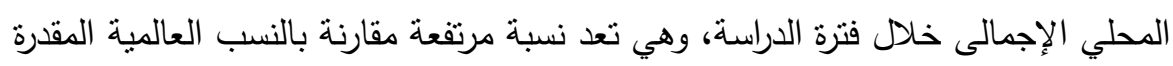

$$
\text { بين (r\% إلي 0\%). }
$$

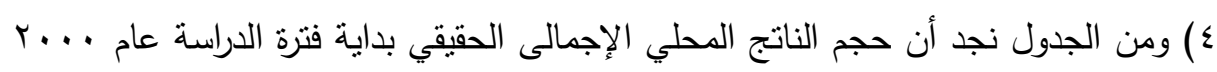

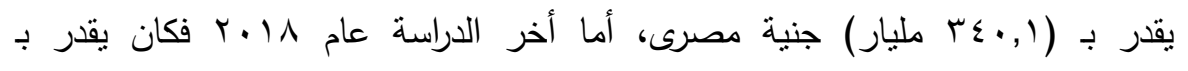

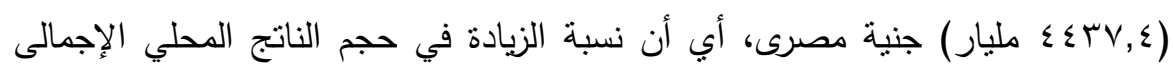

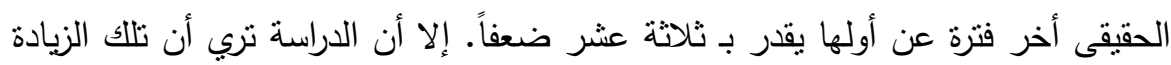

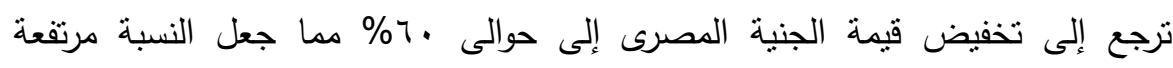

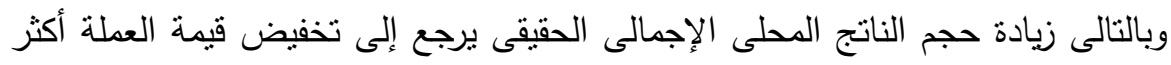
منه زيادة فى الأنتاج. وبما أن حجم الاقتصاد الخفي يمثل نسبة ثابتة من حجم الناتج المحلى الإجمالى الإنى الحقيقى، وهذا يدل على ارتباط زيادة حجم الاقتصاد الخفي بزيادة حجم الناتج المحلى الإنى 
الإجمالى، فبزيادة حجم الناتج يزداد حجم الاقتصاد الخفي وأنه زاد بمقدار( ( ) ضعفاً نتيجة لزيادة حجم الناتج بذلك المقدار • وسوف يزداد حجم الدخل غير المشروع بنفس المقدار ، إلا إذا

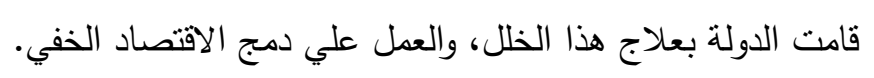
r- تقدير حجم عمليات غسل الأموال في مصر: من خلال النسبة المئوية لحجم عمليات

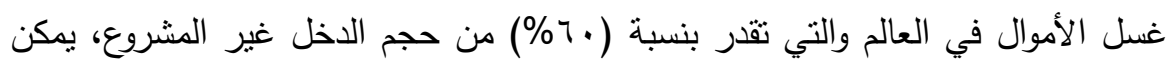

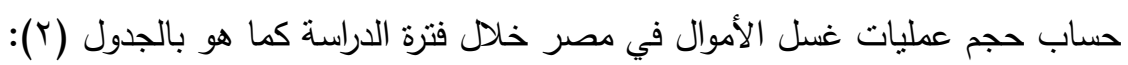

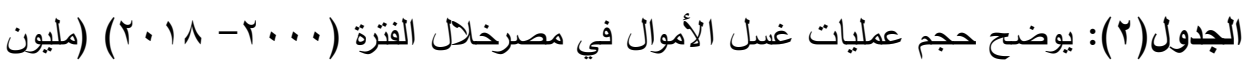

\begin{tabular}{|c|c|c|c|c|}
\hline نسبة حجم عمليات غسل الأموال إلى الاقتصاد & 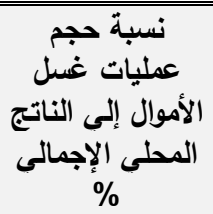 & غُل الأموال & حجم الاخل غير & السنة \\
\hline$r$. & 7,1 & Yrq0T, & rᄉrчו, & $r \ldots$ \\
\hline$r$. & $96 \varepsilon$ & $r \leq r \mid r, r$ & 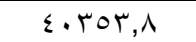 & $r \ldots 1$ \\
\hline$r$. & 7.1 & ro07r,r & $\sum Y \neg \cdot r, \wedge$ & $r \ldots r$ \\
\hline r. & 7,1 & 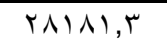 & $\leqslant \neg 97 \wedge, \wedge$ & $r \ldots r$ \\
\hline$r$. & 7,1 & MrVOV,A & $0 \leqslant 097, \pi$ & $r \ldots \varepsilon$ \\
\hline$r$. & 7,1 & 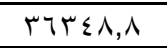 & $7.011, r$ & $r \ldots o$ \\
\hline$r$. & $7, V$ & $\varepsilon 179 \varepsilon, r$ & $79 \leq 91, r$ & $r \ldots T$ \\
\hline$r$. & 7,1 & $0 . Y V \varepsilon,$. & ᄉrVq.,. & $r \ldots v$ \\
\hline$r$. & 7,1 & $7 . \leq \leq 7, r$ & $1 \cdots v \leqslant r, \Lambda$ & $r \ldots \lambda$ \\
\hline$r$. & 7,1 & $V \cdot r \leqslant \Lambda, 0$ & $11 V Y \leq V, 0$ & $r \ldots q$ \\
\hline$r$. & 7,1 & $1) \leq \leqslant 0,0$ & $1 T O V \leq r, 0$ & $r .1$. \\
\hline r. & 7,1 & $q$ q $0 \leqslant q, r$ & $10 \leqslant r \leqslant \Lambda, \Lambda$ & $r .11$ \\
\hline$r$. & 7,1 & $1.7 \pi \leq 7, r$ & $I V \vee Y \leq r, \Lambda$ & $r .1 r$ \\
\hline$Y_{0, \Sigma}$ & $0, V$ & $1 \ldots r \leqslant V, \Lambda$ & $19 \vee Y \leq 7, r$ & $r .1 T$ \\
\hline$r$. & 7,1 & $1 \leqslant r \vee V 0, \cdot$ & หrqтYo,. & $r \cdot 1 \leq$ \\
\hline$r$. & 7,1 & $17 \leqslant 974, \Gamma$ & $r \vee \leq q r \wedge, \wedge$ & $r .10$ \\
\hline$r$. & 7,1 & $1 \wedge Y \wedge \wedge \varepsilon, 0$ & $r \cdot \varepsilon \Lambda \cdot V, 0$ & $r .17$ \\
\hline$r$. & 7,1 & YrEYYO,. & $r q . r \vee o,$. & $r .1 \mathrm{~V}$ \\
\hline$r$. & 7,1 & Y990Y $\leqslant, 0$ & $\varepsilon q 9 r \cdot V, 0$ & $r .11$ \\
\hline
\end{tabular}


المصدر: بيانات حجم الدخل غير الششروع من الجدول السابق رقم ( ()، أما باقي بيانات الجدول تمت

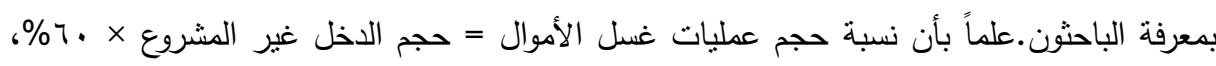

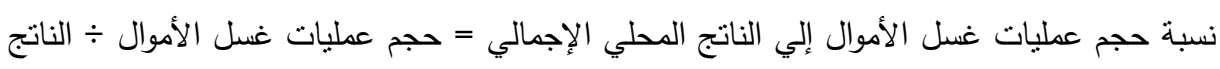

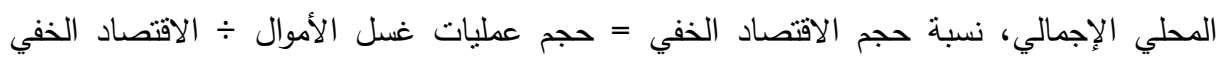

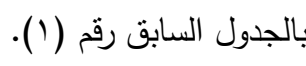

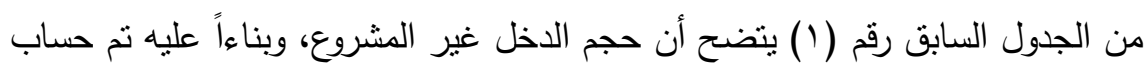

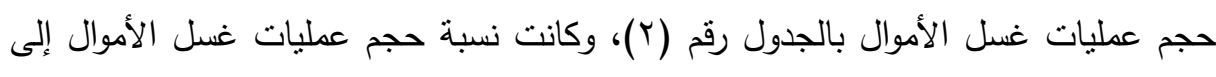

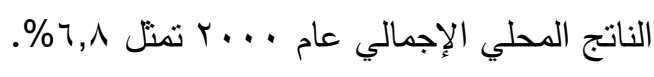

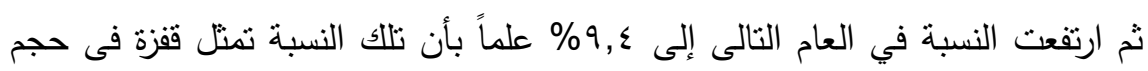

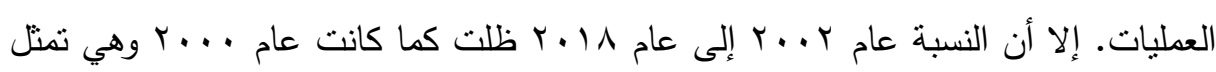

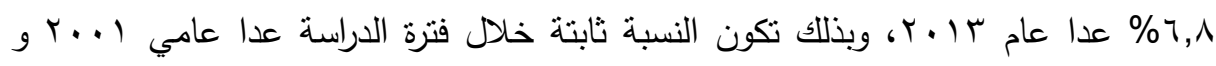

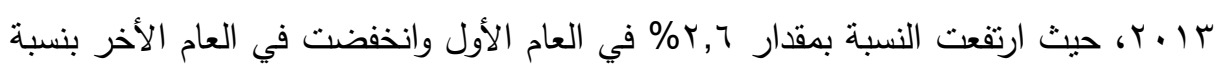
. $\% 1,1$

وتستتنج الدراسة أن نسبة حجم عمليات غسل الأموال إلى الناتج المحلى الإجمالى ثابتة

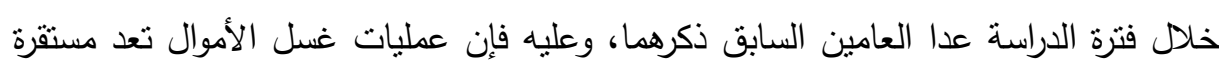

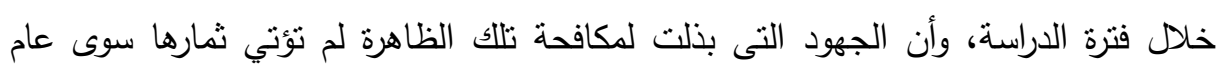

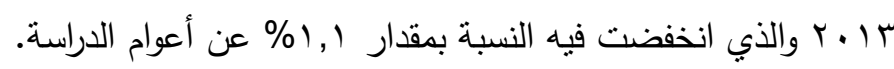

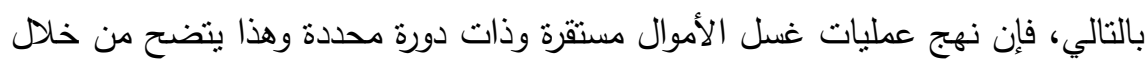
ثبات النسبة، لذا ترى الدراسة أن تلك العمليات ذات دائرة مغلقة يجب العبات العمل على كسرها

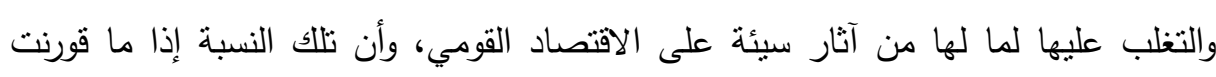

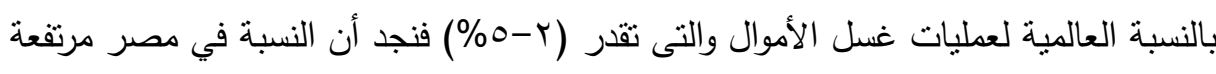

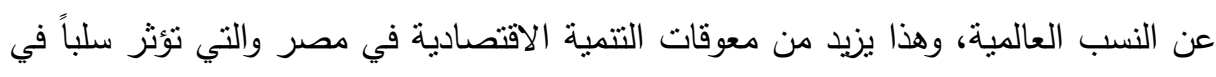
تحقيق التتمية المستدامة.

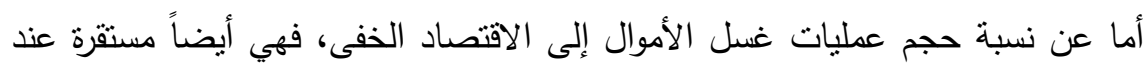

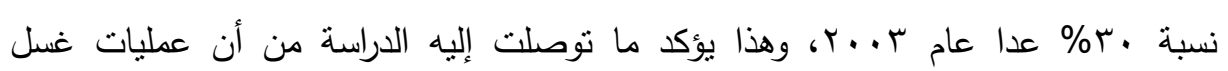




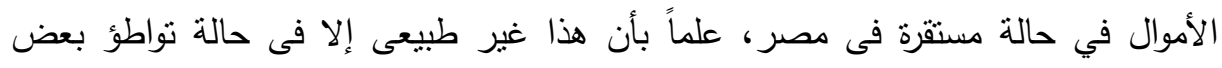

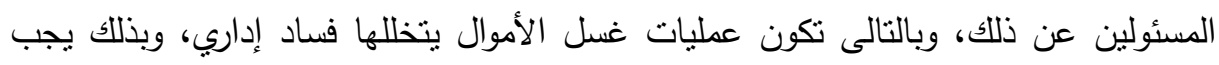
إعادة النظر فى قوانين مكافحة غسل الأموال، وكذلك النظر في إعداد القائمين عليها للتغلب التبات على تلك الظاهرة. ثانياً: الآثار الاقتصادية لعمليات غسل الأموال: لعمليات غسل الأموال آثاراً متشعبة داخل الاقتصاد القومي، فهي تؤثر في عدة قطاعات واتجاهات مختلفة، وهذا ما سنتتاوله في الاني

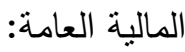
تؤثر عمليات غسل الأموال على المالية العامة من خلال تأثيرها في الإيرادات والنفقات

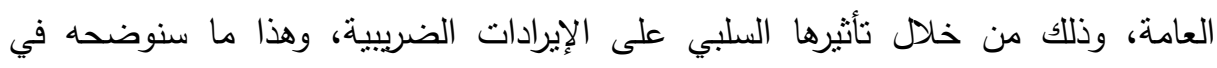

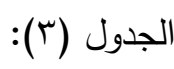


ميلاد برامبل جبره وآخرون

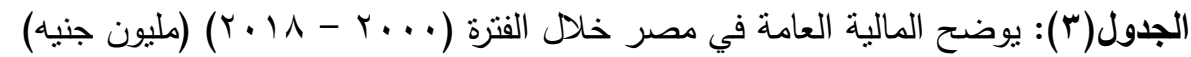

\begin{tabular}{|c|c|c|c|c|c|}
\hline \multirow[b]{2}{*}{ عجز الموازنة } & \multirow[b]{2}{*}{ العقامة } & \multicolumn{3}{|c|}{ الايرادات العامة } & \multirow[b]{2}{*}{ السنة } \\
\hline & & 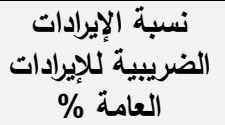 & الإيرادات & الضريبية الإيرادات & \\
\hline IYA.. & - & $T V, \varepsilon$ & VRY.. & $\sum 97 \ldots$ & $r \ldots$ \\
\hline FI $\leqslant \ldots$ & - & $\uparrow \wedge, \wedge$ & $V \leqslant 7 \ldots$ & $011 \ldots$ & $r \ldots l$ \\
\hline roo... & - & $\uparrow \Lambda, \vee$ & vor.. & $018 \ldots$ & $r \ldots r$ \\
\hline КАГ.. & - & $T \Lambda, V$ & Aro.. & ov $\varepsilon \ldots$ & $r \ldots r$ \\
\hline "r... & $1 \leqslant \wedge \wedge \mid \wedge$ & 79,1 & $9 \vee \ldots$ & TV... & $r \ldots \varepsilon$ \\
\hline $017 \ldots$ & 171107 & $V \cdot, \cdot$ & $1.1 \ldots$ & V0T... & $r \ldots o$ \\
\hline $0 . \leqslant \ldots$ & $r . \leqslant \wedge T 0$ & 70,7 & $1 \leqslant 19 \ldots$ & $9 \vee \vee \ldots$ & $r \ldots r$ \\
\hline $0 \leqslant \vee \ldots$ & $r \leqslant \mid \wedge V T$ & $T \varepsilon, \wedge$ & IVTr.. & $11 \leq r \ldots$ & $r \ldots V$ \\
\hline $711 \ldots$ & Y^ะVTI & $\pi, r$ & $1199 \ldots$ & Irv... & $r \ldots \lambda$ \\
\hline$\vee \backslash \wedge \ldots$ & r. Tr. & $09, \varepsilon$ & $r v \leq 0 \ldots$ & $17 r \ldots$ & $r \ldots q$ \\
\hline $9 \wedge \ldots$ & พЧАाVA & $7 \varepsilon, 7$ & rтル人.. & IVR... & $r .1$. \\
\hline IT. . . & rVT & $V Y, q$ & או... & $1919 \ldots$ & $r .11$ \\
\hline $1778 \ldots$ & soT/T० & $V \cdot, 7$ & rqro... & T.VT.. & $r .1 Y$ \\
\hline rrqV.. & orvryo & $V Y, V$ & $r \leq 01 \ldots$ & ro.9.. & $r .1 r$ \\
\hline roos.. & $7 \wedge \mid r \leq V$ & $0 V, 1$ & s07r.. & $r q . r .$. & $r \cdot 1 \varepsilon$ \\
\hline rVqะ.. & VITI... & $70, \mathrm{~V}$ & $\leqslant 700 \ldots$ & r.09.. & $r .10$ \\
\hline rrr.q.. & 1997r & $\mathrm{V}, \mathrm{V}$ & $\leq 91 \leq \wedge \wedge$ & rorrlo & $r .17$ \\
\hline$r .91 \wedge \ldots$ & 97017. & $V 1, r$ & $70911 \varepsilon$ & $\leq 791 \wedge \leq$ & $r .1 V$ \\
\hline$r \mid \leq 1 \ldots$ & - & $\vee \wedge, \cdot$ & $1.0 V \leq 1$ & TrA.人r & $r \cdot 11$ \\
\hline
\end{tabular}

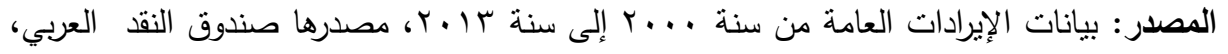

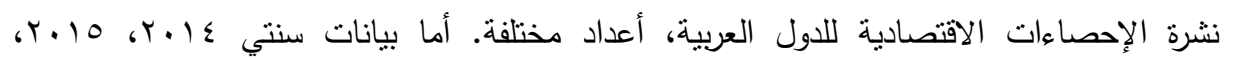

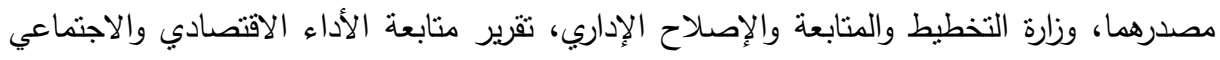

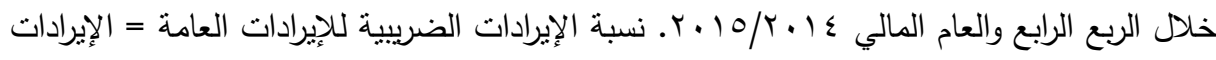
الضريبية بالإيرادات العامة.

من الجدول (ץ) يتضح أن، نسبة الإيرادات الضريبية إلى نسبة الإيرادات العامة تتراوح

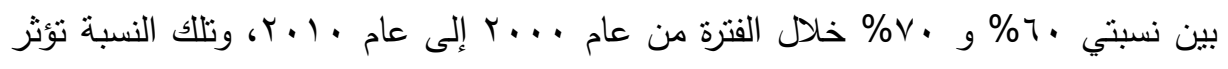

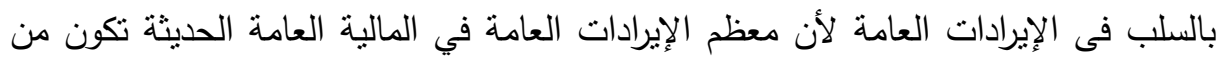

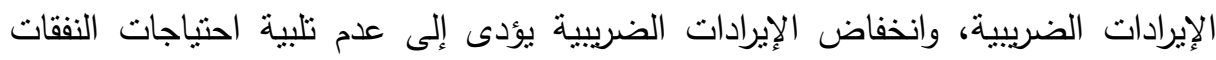

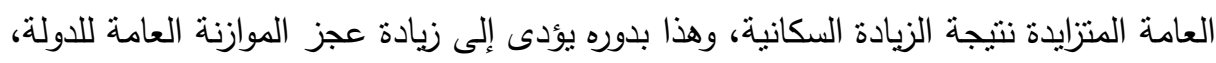
508

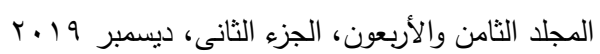


ويؤثر بالسلب في معدلات التتمية الاقتصادية من خله عجز الدولة عن القيام بدورها في

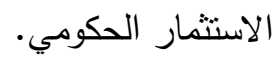

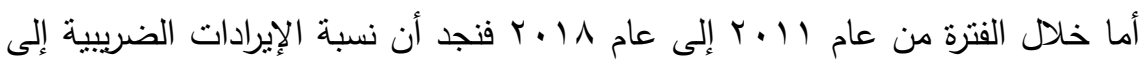

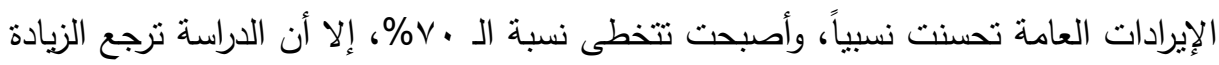
في الإيرادات الضريبية إلى زيادة معدلات التضخم وانخفاض قيمة الجنية المصرى. والدراسة تستتتج أن عمليات غسل الأموال قد أثرت بالسلب فى حصبلة الإدلة الإيرادات

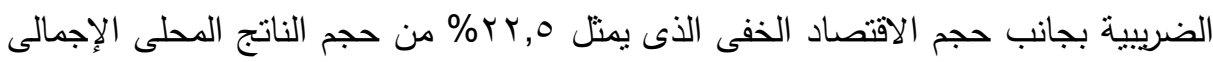

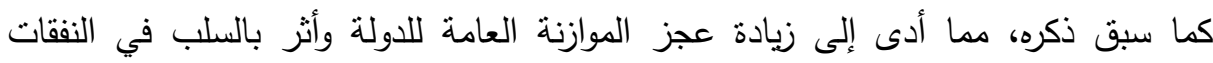

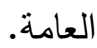

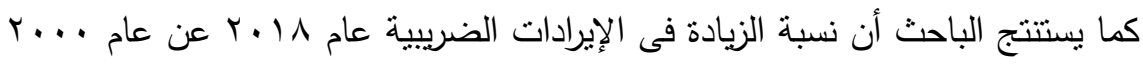

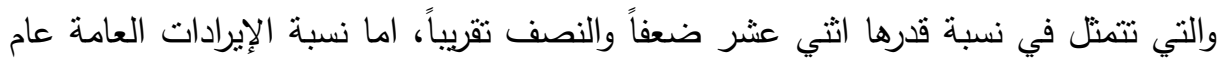

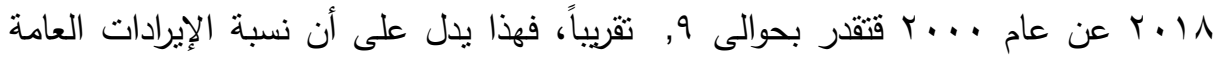

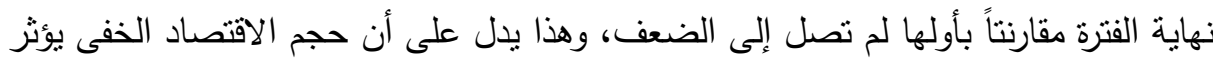

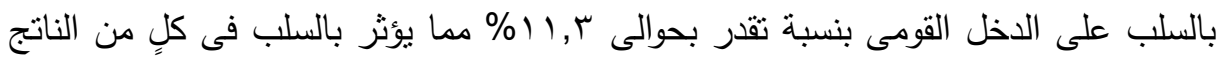
القومى والدخل القومى ومعدلات النمو.

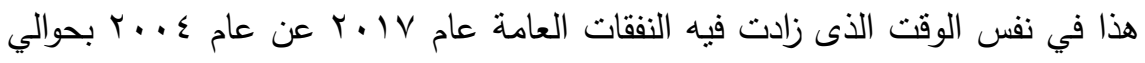

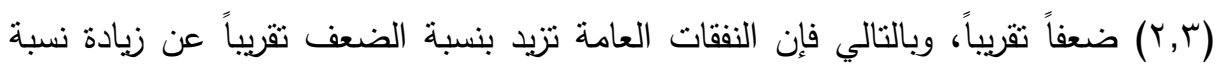
الإيرادات العامة، مما يؤدى إلى زيادة عجز الموازنة العامة للدولة حتى أصبح العجز مزمناً.

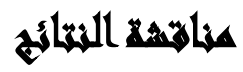

أولاً: نتائج الاراسة التطبيقية: بستعرض الباحث فيما يلي أهم النتائج التي نوصل اليها

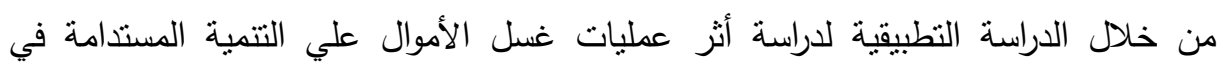
مصر ، ويمكن تقسيم هذه النتائج الى البنود الآتية : 
بعد دراستتا لمختلف الجوانب المتعلقة بكل من عمليات غسل الأموال، وكذا التتمية

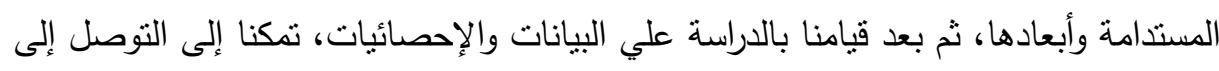

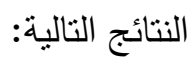

() نساهم عمليات غسل الأموال في هروب رؤوس الأموال إلي خارج البلاد، مما ينتج عنها

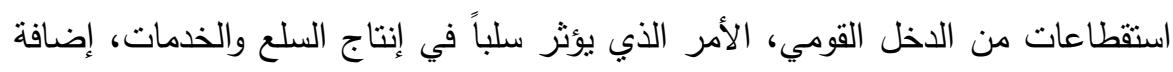

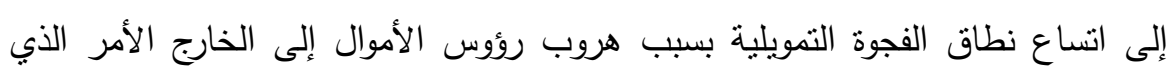

يؤثر بالسلب في الناتج القومي مما يهدد التتمية الاقتصادية وتحقيق التتمية المستدامة.

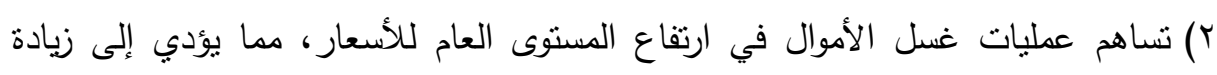

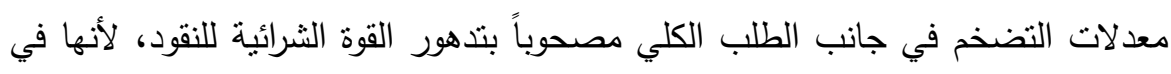
أغلب الأحيان نظل في حالة سيولة مرتفعة وتستتمر في أنشطة تساعد علي إعادة سيولة

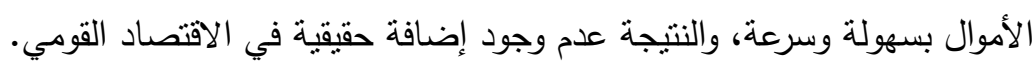

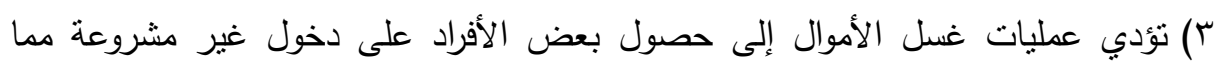

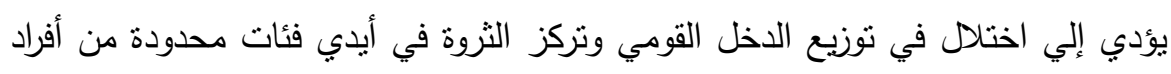
المجتمع، وهذا يعمل على ترسيخ بعض القيم السلبية في المجتمع، وهذا تتبعه مشكلات

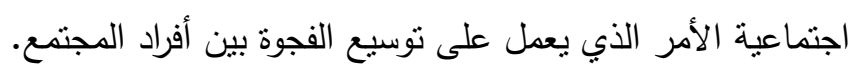

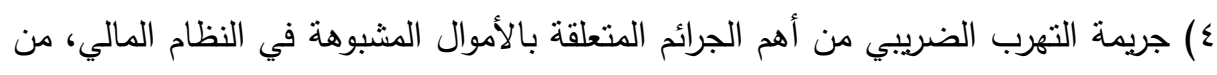

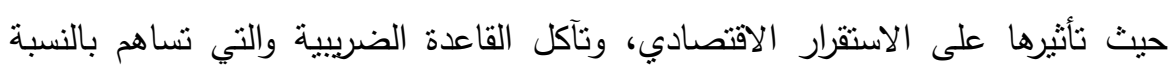
الأكبر في الإيرادات العامة مما يؤدي إلى زيادة عجز الموازئة العادئ العامة للادولة.

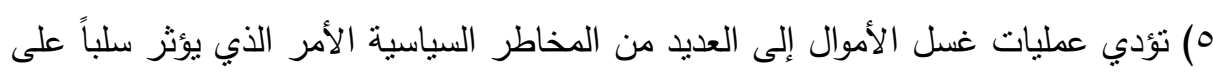

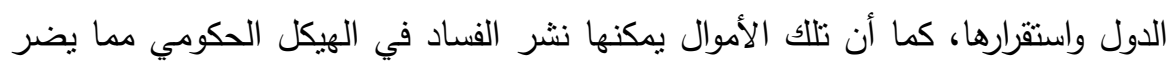

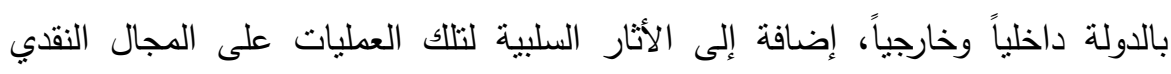

$$
\text { والمصرفي. }
$$

\section{ثانياً: النتائج الخاصة باختبارات الفروض :}

( ) تؤثر عمليات غسل الأموال علي التتمية الاقتصادية من خلال الآثار السلبية علي مؤشرات الاقتصاد القومي. وبهذا يثبت عدم صحة الفرات علئ الفر الأول القائل: 
لا توجد علاقة ذات دلالة بين عمليات غسل الأموال والتنمية الاقتصادية.

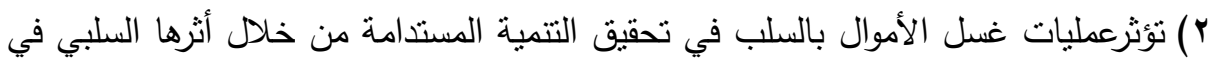

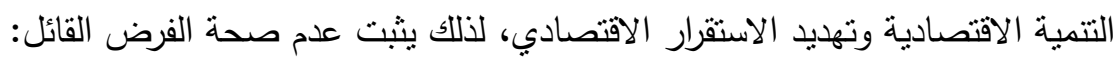
لا توجد علاقة عمليات ذات دلالة بين عمليات غسل الأموال والتتمية المستدامة.

\section{التحوصياهت}

من واقع النتائج السابقة ولتحقيق أهداف الدراسة يستعرض الباحث مجموعة من التوصيات التي يمكن أن نساعد في الحد من أثز عمليات غسل الأموال علي التتمية المستدامة في مصر · المبات ا. العمل على دمج الاقتصاد الخفي في الاقتصاد الرسمي، وذللك من خلال القوانين والتشريعات التي تعمل على تيسير ذللك، إضافة إلى الحوافز الضريبية.

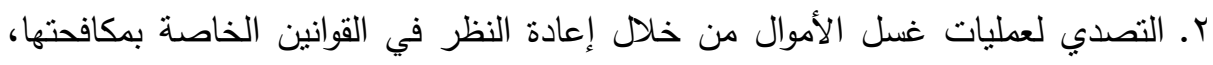
وإعداد وتأهيل القائمين عليها.

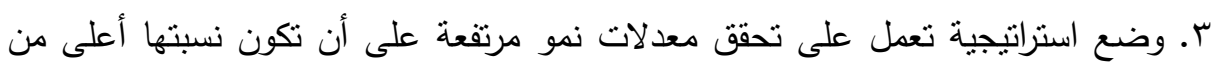

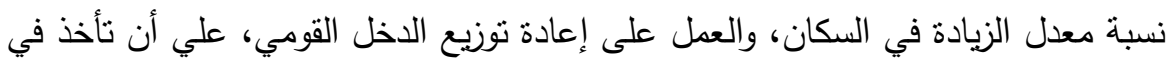

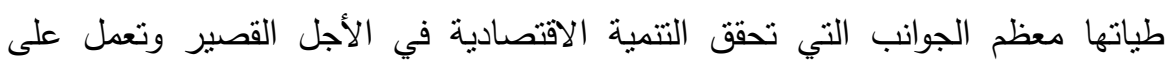
تحقيق التتمية المستدامة في الأجل الطويل.

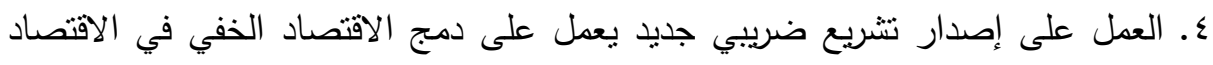

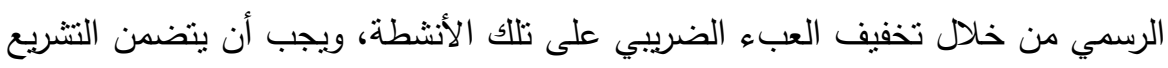
الضريبي الجديد سداد الضرائب المستحقة على تللك الأنشطة حتى وإن كانت مجرمة قانوناً، وأن سداد الضرائب لا يعفي هؤلاء من المسائلة القانونية، لأن الضرائب المستحقة

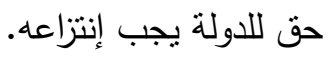




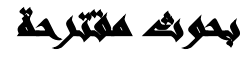

استكمالاً للمسيرة العلمية اقترح الباحثون اجراء عدد من البحوث الهدف منها القاء الضوء

على أثزر عمليات غسل الأموال علي التتمية المستدامة في مصر :

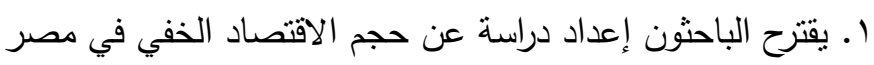

r. يقترح الباحثون دراسات في كيفية دمج الاقتصاد الخفي داخل الاقتصاد الرسمي والاستفادة دراد

منه.

r. يقترح الباحثون ضرورة نوافر آليات الهدف منها الاستفادة الكاملة من كافة القطاعات

الاقتصادية الرسمية والغير رسمية.

\section{المرامئ2}

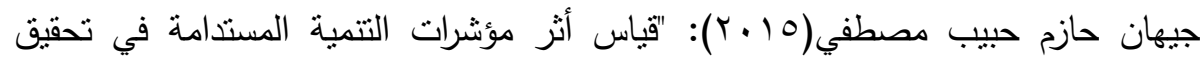

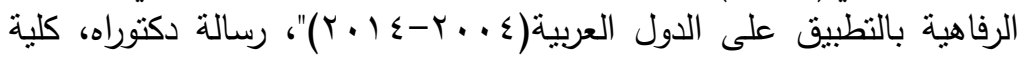

$$
\text { الاقتصاد والعلوم السياسية، جامعة أم درمان، السودان. العان. }
$$

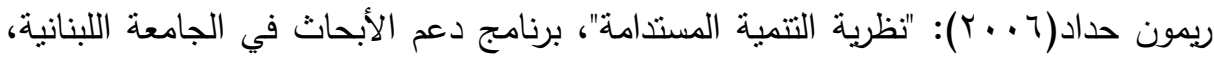

$$
\text { بيروت. }
$$

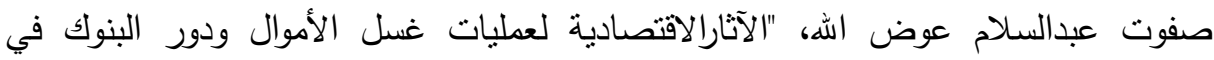

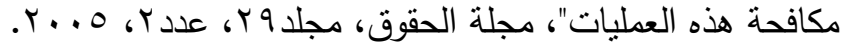

طلال محمود كداوي \& ميادة صلاح الدين ناج الدين، "الأثر المتبادل بين غسيل الأموال

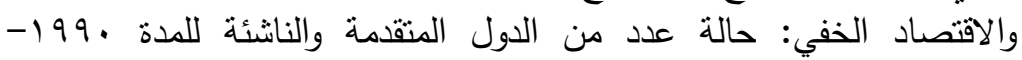

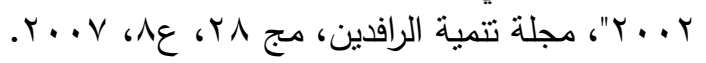

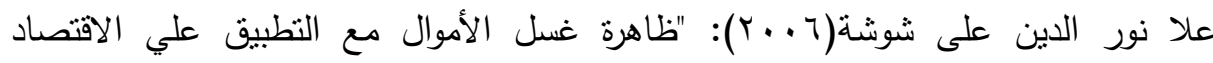

المصري"، رسالة ماجستير ، قسم اقتصاد، كلية التجارة، جامعة عين شمس.

مجيد مسعود( ع191)): "التخطيط للتقدم الاقتصادي والاجتماعي"، المجلس الوطني للتقافة

$$
\text { والفنون والأدب، الكويت، يناير . }
$$

Angela Samantha Maitland Irwin \& Kim-Kwang Raymond Choo,:

"Modelling of money laundering and terrorism financing 
typologies", University of South Australia, Journal of Money Laundering Control, Issue 15, Volum 3, (2012).

Darius Jazepčikas. (2013): "Integrated Scheme of Regional Sustainable Development Drivers.", Faculty of Economics and Management, Aleksandras Stulginskis University, Lithuania, 92, 1.

Michel Dion: "Is money laundering an ethical issue?" Journal of Money Laundering Control 18, no. 4, (2015).

Joyeeta Gupta \& Courtney Vegelin. (2016): "Sustainable development goals and inclusive development." International environmental agreements: Politics, law and economics 16, no. 3 .

M.Michelle Gallant. "Money laundering consequences: Recovering wealth, piercing secrecy, disrupting tax havens and distorting international law." Journal of Money Laundering Control 17, no. 3, (2014).

Norman Mugarura. "Does the broadly defined ambit of money laundering offences globally, a recipe for confusion than clarity?" Journal of Money Laundering Control 19, no. 4, (2016).

Elisabeta Emilia Halmaghi \& Emanoil MUSCALU. (2016): "Economic Dimensions of the Sustainable development." Defense Resources Management in the 21st Century.

musonda simwayi \& muhammed hasee, "the role of financial intelligence units in combating money laundering- a comparative analysis of zambia, zimbabwe and malawi", huazhong university of science and technology, wuhan city, people's republic of china, journal of money laundering control, issue 15, volum 3, (2012).

Navabakhsh, M.\& R. Tamiz, "Influences of rural industries on sustainable social and environmental developments."International Journal of Environmental Science and Technology 10, no. 1, (2013).

Aleksandar Nikolovski, "Sustainable Economic Development in the Transition Countries, With a Retrospect of the Republic of

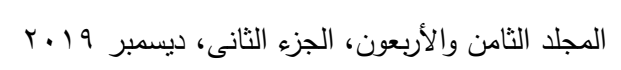


Macedonia." Journal of Economic Development, Environment and People 2, no. 4, (2013).

Jeffrey Simser. "Money laundering: emerging threats and trends." Journal of Money Laundering Control 16, no. 1, (2017).

\title{
THE IMPACT OF MONEY LAUNDERING OPERATIONS ON SUSTAINABLE DEVELOPMENT IN EGYPT
}

\author{
Melad B. Gabra ${ }^{(1)}$; Amr H. Abdel Bar ${ }^{(2)}$ \\ and Mahmoud A. M. Amin ${ }^{(2)}$ \\ 1) Arbah Real Estate Development \& Investment Co 2) Faculty of
} Commerce, Ain Shams University

\begin{abstract}
The study aims to shed light on the negative effects of money laundering operations on sustainable development and the national economy in Egypt. This is achieved by studying the extent of the linkage of money laundering operations, as economic development reflects sustainable development and comprehensive development, because development does not aim to maximize per capita output. But also to achieve the basic needs of individuals, raise their living standards, reduce poverty, reduce the misallocation of national income, and achieve economic and social well-being through the optimal use of resources and reduce unemployment, in addition to justice in Development outcomes are communicated to all members of society while providing productive and social services.

The researchers relied on reports and bulletins issued by (arab Monetary fund, Bulletin of Economic Statistics of Arab Countries, Report on Monitoring Economic and Social Performance at the Ministry of Planning, Follow-up and Administrative Reform) and

$$
\text { المجلد الثامن والأربعون، الجزء الثانى، ديسمبر } 9 \text { ا ـ ب }
$$
\end{abstract}


through some methodological procedures (inductive, deductive, descriptive and analytical), study and analysis of economic indicators of the Egyptian reality during the year (2000-2018), in order to reach the negative effects of money laundering in order to work to reduce or eliminate.

\section{The study reached the following results:}

1. Money laundering negatively affects the achievement of sustainable development through its negative impact on economic development and threatening economic stability.

2. Money laundering has a negative impact on the national economy through a decline in public revenues, which negatively affects the state's ability to meet its obligations, in addition to increasing the gap between production and consumption, as well as the balance of payments gap. Money laundering has negative effects on the national economy.

The most important recommendations of the researcher include the following:

1. Work to integrate the hidden economy into the formal economy through laws and legislation that facilitate this, in addition to tax incentives.

2. Develop a strategy to achieve high growth rates that are higher than the rate of increase in population, and work to redistribute national income, and take into account most aspects that achieve economic development in the short term and work to achieve sustainable development in the long term. 